\title{
Toti-/pluripotential Stem Cells and Epigenetic Modifications
}

\author{
Takashi Tada ${ }^{*}$ and Masako Tada ${ }^{1,2}$ \\ ${ }^{1}$ Department of Development and Differentiation, Institute for Frontier Medical Sciences, Kyoto University, \\ 53 Kawara-cho, Shogoin, Sakyo-ku, Kyoto 606-8507, Japan, and ${ }^{2}$ Precursory Research for Embryonic Sci- \\ ence and Technology (PRESTO), Japan Science and Technology Corporation (JST), Kawaguchi-shi, Saitama \\ 332-0012, Japan
}

\begin{abstract}
The recent fascinating breakthrough in the area of stem cell research is the successful production of cloned animals via nuclear transplantation of somatic nucleus by intrinsic trans-acting factors of oocytes and trans-differentiation of somatic stem cells from adult organs induced by extrinsic growth factors. During the process of nuclear reprogramming, epigenetic modification of the somatic nuclei must be achieved to acquire toti-/ pluripotential competence. However, the molecular mechanism involved is largely unknown. It has been shown that DNA methylation, histone acetylation and chromatin structure are involved in the establishment of epigenetic modification. Now it is evident that they function cooperatively to establish and maintain active or inactive chromatin state. Here we discuss the mechanisms of epigenetic modification potentially involved in the event of nuclear reprogramming.
\end{abstract}

Key words: Stem cell/ES cell/EG cell/transdifferentiation/animal clone/nuclear transplantation/cell hybridization/ DNA methylation/histone acetylation/chromatin structure/reprogramming

Recent developments in the field of stem cell research have been boosted by advances in cloning from somatic cells in mammals, the establishment of primate ES cells, and their differentiation to specific cell types such as dopamine-producing neurons and vascular progenitors for clinical applications in reproductive medicine (Kawasaki et al., 2000; Yamashita et al., 2000). Another rapidly growing field is the understanding of transcriptional regulation and epigenetic modifications, which include DNA methylation, histone acetylation and chromatin remodeling. The isolation and characterization of key molecules involved in these epigenetic modifications indicate that a variety of factors cooperate in the form of large complexes that direct the building of specific nucleosome conformations, which in turn regulate transcriptional activation and repression. Until

\footnotetext{
*To whom correspondence should be addressed: Department of Development and Differentiation, Institute for Frontier Medical Sciences, Kyoto University, 53 Kawara-cho, Shogoin, Sakyo-ku, Kyoto 606-8507, Japan.

Tel: +81-75-751-3821, Fax: +81-75-751-3890

E-mail: ttada@frontier.kyoto-u.ac.jp

Abbreviations: ES, embryonic stem; EG, embryonic germ; EC, embryonal carcinoma; PGC, primordial germ cell; HSC, hematopoietic stem cell; GFP, green fluorescent protein; Dnmt, DNA methyltransferase; MeCP, methylated-DNA-binding protein; MBD, methyl-CpG-binding domain; HAT, histone acetylase; HDAC, histone deacetylase; SWI/SNF, ATPdependent chromatin remodeling complex.
}

recently the fields of stem cell research and epigenetic research have been developed independently. However, it is now evident that these fields should no longer be viewed separately. It is likely that the mechanisms by which toti-/ pluripotential stem cells maintain their characteristic nuclear state, which gives them the competence to differentiate into multiple cell types, is different to the regulatory mechanisms found in somatic cells. The epigenetic state of toti-/ pluripotential stem cells and cloned somatic nuclei could be explained, at least in part, by the latest findings relating to chromatin remodeling. Here, we will present an overview of the research into stem cells and epigenetic modifications in an attempt to bring these two rapidly evolving fields closer together.

\section{Pluripotential stem cells; ES and EG cells}

Pluripotential stem cells of the mouse are continuously maintained in an undifferentiated state, and are capable of largely increasing in number through rapid cell divisions. Under appropriate conditions these cells will differentiate into ectodermal, mesodermal and endodermal derivatives in the formation of embryoid bodies following in vitro suspension culture, and in teratoma formation by in vivo transplantation (Martin, 1980). Classically, pluripotential stem cells 
were isolated from mouse teratocarcinomas, and were termed embryonal carcinoma (EC) cells (Pierce, 1967). Other cell lines, which have similar properties to EC cells were first isolated from the inner cell mass (ICM) of mouse blastocysts. Importantly, the production and isolation of these cells, originally termed EK cells (Evans and Kaufman, 1981), and later embryonic stem (ES) cells (Martin, 1981), did not require carcinogenesis (Fig. 1). ES cells maintain a normal karyotype through numerous cell divisions in culture, and will efficiently contribute to the somatic and germ cell lineages of chimeras following their reintroduction into recipient mouse blastocyst ICMs. In addition, homologous recombination will occur in mouse ES cells with very high efficiency. Thus, research using ES cells has provided enormous biomedical benefits through the in vitro manipulation of the genome, by allowing for a greater understanding of complex biological systems in vivo using transgenic and knockout mice (Capecchi, 1989). More recently a third type of pluripotential stem cell line, embryonic germ (EG) cells, was established from primordial germ cells (PGCs) in the mouse embryo, both migrating and shortly after entry into the gonads (Matsui et al., 1992; Resnick et al., 1992) (Fig. 1). Similar to ES cells, EG cells are able to efficiently colonize chimeric embryos, and their genomes can be successfully transmitted to the next generation (Labosky et al., 1994; Tada et al., 1998). However, the epigenetic state of
EG cells derived from gonadal PGCs is different to that of ES cells, and EG cell chimeras show phenotypic abnormalities, which include fetal overgrowth and skeletal malformation. This can be explained, at least in part, by the associated bi-allelic expression/repression of some imprinted genes, which are transcribed according to their parental-origin (Tada et al., 1998). The three types of pluripotential stem cells, EC, ES and EG, resemble each other in phenotype, characterised by a large nucleus and small amount of cytoplasm, and the retention of a robust capacity for proliferation.

In other mammalian species, including rat (Vassilieva et al., 2000), rabbit (Schoonjans et al., 1996), pig (Shim et al., 1997; Chen et al., 1999), sheep (Notarianni et al., 1991) and cow (Iwasaki et al., 2000), ES-like and EG-like cells have been established for the purpose of cell-mediated transgenesis, to include the production of animal models for human diseases, bioreactors for production of human therapeutic proteins, organ donors for transplantation into humans, and livestock which produce valuable products with high efficiency. In the world of primates, ES cells have been successfully derived from blastocysts of the rhesus monkey (Thomson et al., 1995), the common marmoset monkey (Thomson et al., 1996) and the cynomolgus monkey (Suemori et al., in press). The successful establishment of human ES cells from blastocysts (Amit et al., 2000; Thom-

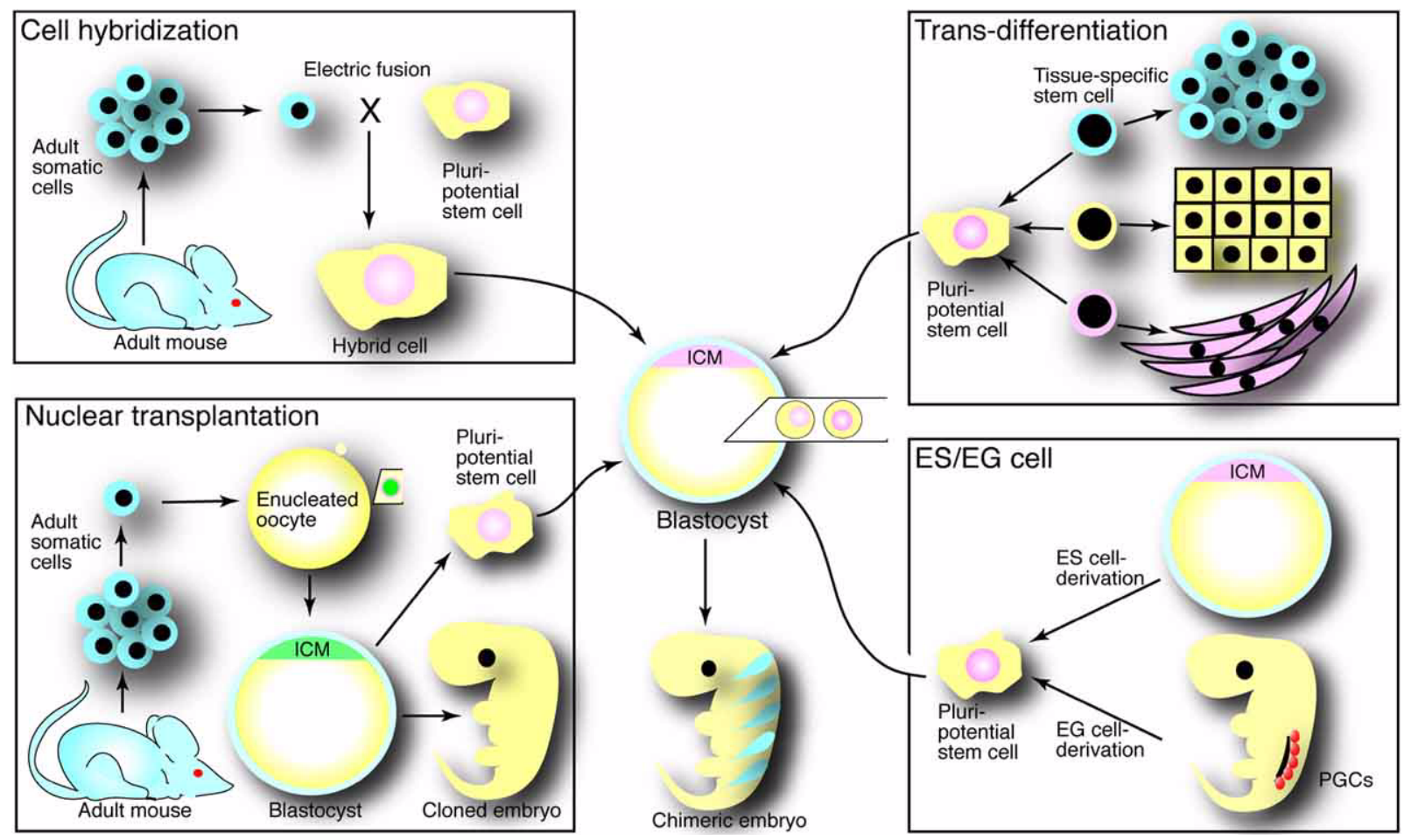

Fig. 1. Derivation of pluripotential stem cells. Nuclei of adult somatic cells acquire pluripotential competence by epigenetic reprogramming via cell hybridization with pluri-potential stem cells and nuclear transplantation to enucleated oocytes. Tissue-specific multipotential stem cells are capable of transforming to pluripotential stem cell by extrinsic stimulation as similarly seen by ES and EG cell derivation from the inner cell mass cells of blastocysts and primordial germ cells. Pluripotency of these cells is shown by differentiation to various types of tissues in chimeras. 
son et al., 1998), and human EG cells from PGCs of 5-9 week old embryos (Shamblott et al., 1998) have also been reported. In conclusion, the ICM cells of mammalian blastocysts appear to have a common capacity for transformation into pluripotential stem cells when kept under appropriate culture conditions in vitro.

\section{Transdifferentiation of somatic stem cells}

The most powerful stem cell is the totipotent fertilized oocyte, which grows and differentiates into every type of complex, functionally distinct, multicellular tissue during whole body formation. Even after complete maturation some somatic cells retain stem cell-like properties. These are, however, restricted in their differentiating potential and play an important role in maintaining homeostasis of many tissues and organs by regeneration during defined self-renewal and following tissue damage. Primitive animals have a very powerful ability for self-regeneration. For instance, planarians and hydrozoans can rebuild a perfect body from small fragments, and some amphibians and reptiles can regenerate whole body parts, including the tail and limbs. In birds, some neurons retain the potential for regeneration. However, self-regenerative activity has, until recently, been less notable in mammals. Hair, skin, small intestine and hematopoietic cells chronologically divide, terminally differentiate, and die. It has therefore been long suspected that a subpopulation of somatic stem cells may be maintained in these tissues in mammals. Surprisingly, however, recent stem cell research has revealed that the ventricular system of the fore- and midbrain, hippocampus and the spinal cord also retain multipotential stem cells, as shown by the generation of neurons, glia and oligodendrocyte progenitor cells in culture (Temple and Alvarez-Buylla, 1999; Momma et $a l ., 2000)$. This contradicts the long held-notion that mammalian neurogenesis ceases in embryonic and early postnatal development. The precise nature of adult neural stem cells, including their location, function and how their proliferation is regulated is, however, largely unknown. More surprisingly, adult neural stem cells retain the potential to differentiate into all germ layers, including various types of somatic tissue, in addition to the neural cell lineage (Clarke et al., 2000). The neural stem cells were isolated in vitro as neurospheres from adult brains of ROSA26 transgenic mice, which carry the ubiquitously expressed neo/lac $Z$ reporter gene. These were introduced into the amniotic cavity of early chick embryos and the blastocoel cavity of mouse blastocysts. X-gal staining of the chick and mouse manipulated embryos clearly showed that the adult neural stem cell derivatives contributed to many embryonic tissues, similar to that seen in ES cell chimeras. The neural stem cells therefore possess the potential to transdifferentiate into pluripotential stem cells.

This intriguing transdifferentiation phenomenon is also evident in hematopoietic stem cells (HSCs). HSCs, which are one of the most well-characterised populations of somatic stem cells, are responsible for maintaining blood cell formation by self-renewal and multilineage differentiation in the bone marrow, fetal liver and thymus. Rat bone marrow-derived HSCs are transformed in vitro to hepatocytelike cells following treatment with high concentrations of hepatocyte growth factor (Oh et al., 2000). More interestingly, two independent research groups demonstrated the emergence of hepatocytes from donor bone marrow cells following transplantation into lethally irradiated rat (Petersen et al., 1999) and mouse (Lagasse et al., 2000) recipients. The emergence of hepatocytes positive for dipeptidyl peptidase (DDP) IV in the liver of DDPIV-negative female rats rescued by bone marrow transplantation from DDPIV-positive male rats was confirmed by histochemical analysis using a Y-chromosome-specific DNA probe and an antibody against DDPIV. In mice, regeneration of donor-derived hepatocytes was detected in recipient fumarylacetoacetate hydrolase $(\mathrm{FAH})$-deficient mice following transplantation of whole bone marrow cells, and by intravenous injection of enriched bone marrow cells carrying surface markers specific to HSCs isolated from ROSA26 transgenic mice. These mice also showed significant improvements in FAH associated symptoms.

Thus, somatic stem cells, including those from neural and hematopoietic lineages, retain the potential to transdifferentiate into pluripotential stem cells by extrinsic induction signals (Fig. 1). Adult stem cells therefore have properties that are more closely related to those of embryonic stem cells than previously imagined.

\section{Nuclear reprogramming of somatic cells via nuclear transfer}

The transfer of somatic cell nuclei into unfertilized oocytes is one possible approach towards generating totipotential cells classically known as cloned embryos. The production of cloned animals was first achieved more than 30 years ago in amphibians. Cloned frogs were generated by nuclear transfer of the intestinal endoderm of feeding tadpoles into activated enucleated eggs (Gurdon, 1962). Vital to this process was the successful reprogramming of the somatic cell nucleus by the egg cytoplasm. More recently, the nuclear reprogramming capacity of oocytes has been demonstrated in mammals by the production of cloned sheep, cows, mice and pigs (Wilmut et al., 1997; Kato et al., 1998; Wakayama et al., 1998; Onishi et al., 2000; Polejaeva et al., 2000) (Fig. 1). Thus, nuclear reprogramming is not an uncommon phenomenon.

Recent technical developments in the transfer of somatic nuclei have provided a new approach for cell-mediated transgenesis, since the nuclei of cultured somatic cells (as for ES cells) can be genetically manipulated in vitro before transfer into enucleated oocytes (McCreath et al., 2000; Rideout et al., 2000). Thus, both nucleo-cytoplasmic 
hybrids and somatic cell-mediated transgenic animals could be generated using this approach, in mammalian species in which the establishment of ES cells is not currently feasible. One biomedically valuable advantage of this technique is the production of ES cells derived from blastocysts cloned from somatic cells (Munsie et al., 2000; Kawase et al., 2000). The genotype of these ES cells is identical to that of the original somatic cell, and therefore the immune system of the somatic cell donor will be completely tolerant to the ES cell derived from the cloned blastocyst.

In mice cloned from somatic nuclei one effect of reprogramming is alterations in activity of the X-chromosome. $\mathrm{X}$-chromosome inactivation during early embryogenesis coincides with changes in epigenetic modifications, including a delay of DNA replication to the later stages of $\mathrm{S}$ phase (Takagi et al., 1982), DNA hypermethylation (Jones, 1999) and histone H4 hypoacetylation (Keohane et al., 1998). An $\mathrm{X}$-chromosome that is inactivated in a female somatic cell is reactivated in cloned preimplantation mouse embryos (Eggan et al., 2000), indicating that epigenetic reprogramming has occurred in the cloned cells. Other features of cloning include the extension of telomeres in cloned calves, when compared to cells from age-matched, noncloned animals (Lanza et al., 2000). Indeed, telomere shortening was not evident even after six rounds of sequential cloning in mice (Wakayama et al., 2000). Telomere extension, which normally occurs during germline development, would therefore appear to be tightly regulated in cloned animals, although the mechanism by which this occurs is not understood.

Highly differentiated somatic cells are normally incapable of transformation to pluripotential stem cells by extrinsic induction. The successful production of cloned animals from such cells, however, demonstrates that the mammalian unfertilized oocyte contains powerful factors that are capable of reprogramming somatic nuclei from a fully differentiated state to a toti-/pluripotential state.

\section{Nuclear reprogramming of somatic cells by cell hybridization}

Similar to the production of cloned animals from somatic nuclear transfer, the epigenetic state of a somatic nucleus can be heritably reprogrammed to that of a pluripotential stem cell by hybridization of the two cell types (Fig. 2A). In cell hybrids generated by the fusion of gonadal PGC derived EG cells and thymic lymphocytes (Tada et al., 1997), the methylation of imprinted genes, non-imprinted genes and repetitive sequences scattered throughout the genome is erased. In addition, tissue-specific gene expression is lost and the somatic nuclei acquire pluripotential stem cell-like properties, as shown by their competence to differentiate into the three primary germ layers of the developing embryo. Hybridization of thymic lymphocytes to ES cells also leads to acquisition of pluripotential competence to differentiate into various tissues (Tada et al., in preparation).
(Fig. 2C). Thus, both types of pluripotential stem cell retain a common capacity to reprogram somatic nuclei through the action of transacting factors. It is notable, however, that the allele-specific methylation pattern associated with many imprinted genes is maintained in the somatic nuclei of ES hybrid cells. This finding differs significantly from the dominant effect of an EG cell on a somatic nucleus, and indicates that "embryonic type" and "germ cell type" reprogramming occurs in ES and EG hybrid cells, respectively. When ES cells are hybridized with thymic lymphocytes carrying an inactive Oct4-GFP transgene, which is an ideal marker for the identification of toti-/pluripotential stem cells (Yeom et al., 1996; Yoshimizu et al., 1999), the Oct4 gene is reactivated within 48 hours (Fig. 2B). This time-lag suggests that DNA replication and cell division may be a central requirement for induction of reactivation. Thus, nuclear reprogramming of somatic cells can be induced not only by factors present in oocyte cytoplasm, but also by transacting factors derived from ES and EG cells.

\section{Extrinsic and intrinsic factors for producing the toti-/pluripotential stem cell}

Toti-/pluripotential stem cells are capable of differentiating into a variety of cell and tissue types essential for support of body formation. However, the different toti-/pluripotential stem cells, which possess similar properties to each other, are likely to be produced in different ways reflecting their different cellular origins. ES and EG cells, and pluripotential stem cells transdifferentiated from somatic stem cells, can all be transformed by the action of extrinsic signals. Conversely, the nuclear reprogramming of somatic cells is induced by cellular factors intrinsic to the unfertilized oocyte, ES cell and EG cell in cloning and hybridization.

Induction of toti-/pluripotential stem cells by extrinsic signals occurs in vivo during mouse germ cell development. In the eggs of Drosophila melanogaster, Caenorhabdities elegans and Xenopus laevis, the germcell determinant, germ plasm (polar plasm), is accumulated as a maternal factor. However, it is believed that mouse eggs do not contain such a factor (Snow and Monk, 1983), suggesting that germ cell and somatic cell lineages are not committed in the early mouse embryo. PGCs are first detected biochemically as alkaline phosphatase-positive cells localized in the extraembryonic mesodermal region, posterior to the primitive streak of the E7.25 embryo (Ginsburg et al., 1990). It is largely unknown how and when the PGCs are initially determined in the implantation embryo. However, transgenic mice deficient for the Bmp4 gene, whose expression is first detected in the extraembryonic ectoderm next to the epiblast of E5.5 embryos (Lawson et al., 1999), do not form PGCs. It is therefore likely that some signals, including BMP4, secreted from the extraembryonic ectoderm induce the formation of PGC precursors in the adjacent embryonic ectoderm. This hypothesis is supported by recent in vitro primary cul- 

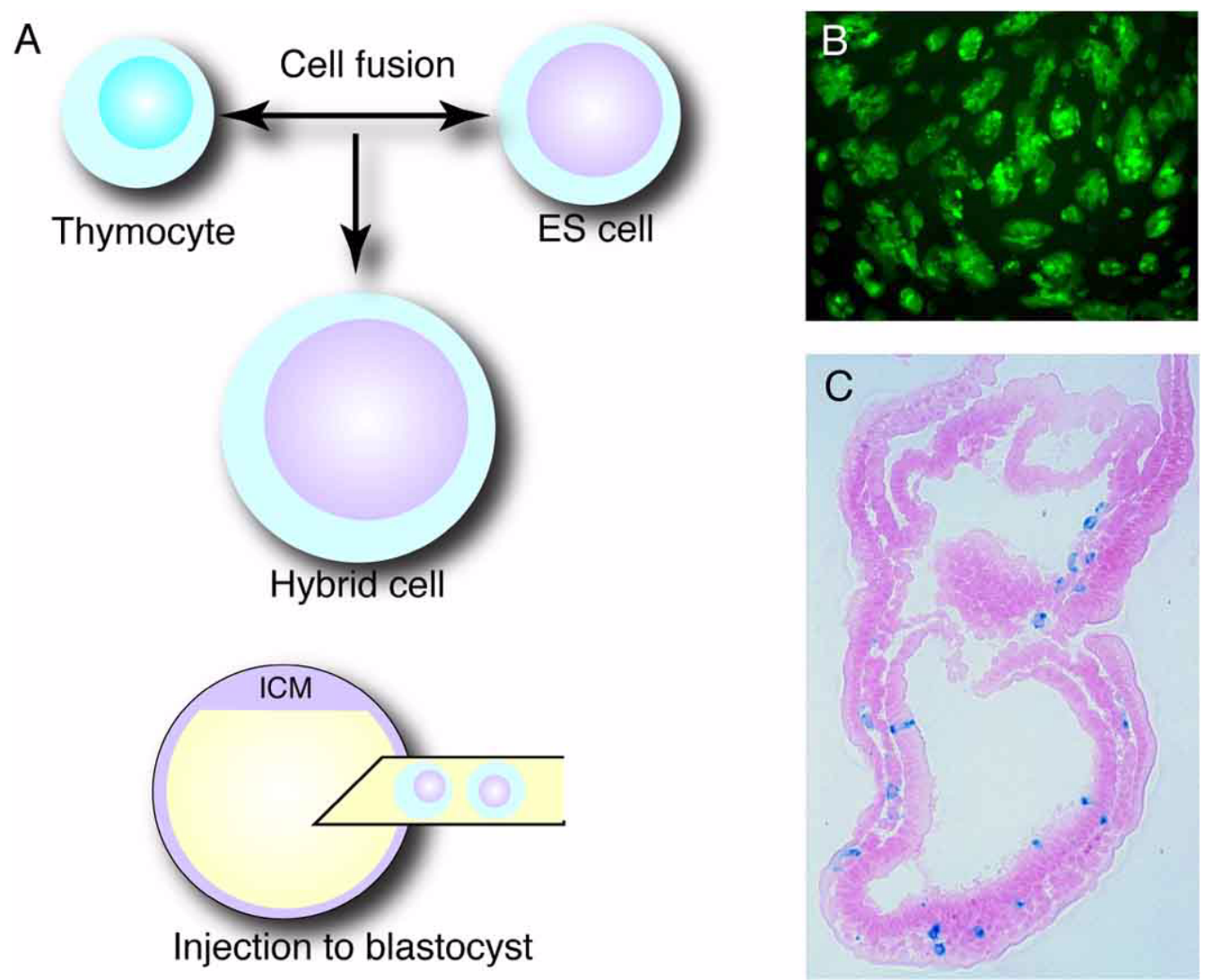

Fig. 2. Nuclear reprogramming of somatic nuclei by cell hybridization with ES cells. (A) Experimental strategy for generating ES x thymocyte hybrid cells and for producing chimeras by blastocyst injection. (B) Reactivation of the Oct4-GFP reporter gene, which is a marker for identification of pluripotential stem cells, in ES x thymocyte hybrid cells. Oct4-GFP repressed in thymocytes is expressed in all ES hybrid cells. (C) Pluripotential competence of ES x thymocyte hybrid cells as shown by contribution to the three primary embryonic germ layers in E7.5 chimeras. The hybrid cell derivatives are detected as scattered blue cells by X-gal staining in a semithin section of chimeric embryo.

ture experiments on explanted embryos at the prestreak stage (Yoshimizu et al., 2001). Epiblasts dissected from E5.5 embryos, combined with extraembryonic ectoderm tissue, gave rise to clusters of PGC-like cells positive for alkaline phosphatase activity, whereas such cells were not detected in cultured E5.5 epiblasts without extraembryonic ectoderm. Therefore, differentiation of the primary epiblast cells into PGCs, the precursor cells of totipotential germ cells, is triggered by extrinsic factors secreted from the extraembryonic ectoderm.

Blastocysts, which are composed of trophoblast cells (extraembryonic tissue precursors) and pluripotential ICM cells (embryonic tissue precursors), develop into an egg-cylinder stage embryo shortly after implantation. While the ICM cells of preimplantation embryos are capable of transforming into ES cells, the epiblast cells of the early postimplantation embryo are not. The derivation process of ES cells from ICM cells is not fully understood. It is known, however, that supplementary signals added either directly to the medium (leukemia inhibitory factor (LIF)) or derived from fibroblast feeder cells, are required for successful ES cell derivation. Additional signals are also required for the successful derivation of mouse EG cells, including fibroblast growth factor (FGF) and LIF (Matsui et al., 1992; Resnick et al., 1992). In the transdifferentiation of neural stem cells, extrinsic FGF and epidermal growth factor (EGF), supplied in the culture medium, stimulate rapid proliferation in vitro (Doetsch et al., 1999; Johansson et al., 1999; Clarke et al., 2000). Thus, extrinsic inductive factors play key roles in restoring and maintaining the pluripotential stem cell properties on cells derived from PGCs and the stem cells of adult organs, which are relatively undifferentiated in comparison to typical somatic cells. It is, however, not evident that the same factors are involved in their maintenance in vivo.

Stimulation by extrinsic factors does not allow the acquisition of pluripotential stem cell properties on considerably differentiated somatic cells. Toti-/pluripotential stem cells with somatic nuclei can be produced only via nuclear reprogramming using the nuclear transplantation technique discussed above (Wilmut et al., 1997; Kato et al., 1998; Wakayama et al., 1998; Onishi et al., 2000; Polejaeva et al., 2000) and in vitro cell hybridization between pluripotential 
stem cells and somatic cells (Tada et al., 1997; Tada et al., in preparation). Thus, intrinsic factors stored in the host toti-/pluripotential cells are required for remodeling the epigenetic modifications of the somatic nuclei.

\section{Regulation of epigenetic modification}

The epigenetic status of stem cells and adult somatic cells from different developmental stages is modified to that of a toti-/pluripotential stem cell, whether stimulated by extrinsic or intrinsic factors. Recent developments concerning epigenetic modifications reveal that DNA methylation, histone acetylation and chromatin remodeling are intimately linked to regulate gene-specific transcriptional activation and repression.

DNA methylation, which is one of the most well-characterized epigenetic modifications associated with transcriptional repression, and is heritable through cell divisions, occurs at the 5'-cytosine residue of $\mathrm{CpG}$ dinucleotides in vertebrate genomes (Boyes and Bird, 1991). In mammals, a global erasure mechanism shortly after fertilization results in very low levels of methylation, which is maintained through preimplantation development. After implantation, genome-wide remethylation occurs by a wave of de novo methyltransferase activity in the somatic cell lineages (Monk et al., 1987; Razin and Kafri, 1994). In the germ cell lineage, a second round of erasure demethylates the vast majority of methylated sites prior to meiosis, after the PGCs have colonized the genital ridges (Kafri et al., 1992; Brandeis et al., 1993). The methylation event in postimplantation embryos and the demethylation event in gonadal PGCs are accompanied by inactivation and reactivation of one $\mathrm{X}$ chromosome, respectively, in a normal female cell (Monk and Harper, 1979; Monk and McLaren, 1981). This is accompanied by the establishment and switching of genomic imprints, which regulate the parental-origin-specific methylation and repression of imprinted genes (Brandeis et al., 1993; Szabo and Mann, 1995; Tada et al., 1998; Obata et al., 1998; Tada et al., 2000). Stable inheritance of methylation patterns from parental DNA to daughter DNA is due to the abundant enzymatic activity of the maintenance methyltransferase (Dmnt1). This enzyme preferentially recognizes hemimethylated $\mathrm{CpG}$ residues and faithfully recruits methylation to newly synthesized DNA (Bestor, 1988). The embryonic lethal phenotype found in mice deficient for Dnmtl clearly demonstrates that methylation is crucial for appropriate regulation of gene expression, most likely by altering the accessibility of transcriptional machinery to the genes (Li et al., 1992, 1993; Howell et al., 2001). However, it is likely that additional methyltransferase enzymes, in conjunction with Dnmt1, control global methylation patterns since some residual de novo methylation is seen in Dnmt1 deficient ES cells. Indeed, two further enzymes, Dnmt3a and Dnmt3b, have been identified recently, both of which carry a methyltransferase domain (Okano et al.,
1998). Disruption of these genes resulted in embryonic lethality even though the activity of Dnmt1 was not affected (Okano et al., 1999). In the dynamics of methylation, how demethylation is regulated remains unknown. To form a stable inactive chromatin structure for gene repression, the methylated-DNA-binding protein complex, $\mathrm{MeCP} 1$, and the $\mathrm{MeCP} 2$ protein, are required. Both of these contain a methyl-CpG-binding domain (MBD) (Nan et al., 1993). $\mathrm{MeCP} 2$, which has a high affinity for single symmetrically methylated $\mathrm{CpG}$ dinucleotides, plays an important role since high degree chimeras with $\mathrm{MeCP} 2$-deficient ES cells are embryonic lethal between E8.5 and E12.5 (Tate et al., 1996). Interestingly, unlike the Dnmt1-deficient mice, these chimeras did not show biallelic expression of imprinted genes or ectopic activation of the Xist (X inactive-specific transcript) gene in male ES cells (Li et al., 1993; Beard et al., 1995), suggesting that other MBD-related genes play redundant roles. To date, four genes have been identified in mice and humans which carry MBD related sequences, $M B D 1, M B D 2, M B D 3$ and MBD4. MBD1, MBD2 and $M B D 4$ bind specifically to methylated DNA in vitro and in vivo (Cross et al., 1997; Hendrich and Bird, 1998). Distinctive functions for MBD2, which is a component of the MeCP1 protein complex (Ng et al., 1999) and the closely related MBD3 protein, which is a component of the Mi-2/ NuRD co-repressor complex (Tong et al., 1998; Zhang et al., 1998; Wade et al., 1999), have been revealed by gene disruption experiments. Mbd2-deficient mice were viable and fertile, whereas $M b d 3$-deficient mice died before E8.5, suggesting that MBD3 is a key component of Mi-2/NuRD, while MeCP1 is recruited to DNA by factors other than MBD2 (Hendrich et al., 2001).

Important progress has been made in understanding the mechanism of chromatin remodelling by interactions between DNA methylation and histone deacetylation. In general, histone acetylation, through the action of histone acetylases (HATs), correlates with gene activation. Conversely deacetylation, via histone deacetylases (HDACs), correlates with gene silencing (Turner, 1993; Wolffe, 1996; Fry and Peterson, 2001). The histone acetylation status of conserved lysine residues in the amino-terminal domains of histones H3, H4, H2A and H2B directly contributes to transcriptional regulation. However, the molecular mechanisms underlying the effects of histone acetylation and deacetylation on transcription are not fully understood. Acetylated amino-terminal domains extending from the surface of the nucleosome contribute to nucleosome destabilisation (Bauer et al., 1994) and disruption of higher-order compaction of nucleosomal arrays (Tse et al., 1998) without altering histone-histone interactions and disruption of nucleosome assembly. A remarkable hallmark in the field of gene regulation is that $\mathrm{MeCP} 2$ recruits a corepressor complex containing HDACs and mSin3A (Nan et al., 1998; Jones et al., 1998). Thus, two mechanisms of gene repression, involving methylated chromatin and de-acetylation of core histones, 
are bridged through the direct or indirect mediation of mSin3A. Similarly, cooperation of HDACs and MBD1, MBD2 and MBD3 may also be involved in the mechanism of gene silencing (Newell-Price et al., 2000; Ballestar and Wolffe, 2001). The HDAC-dependent pathway is at least in part responsible for transcriptional repression.

A recent study shows a link between chromatin remodeling, methylation and gene expression in mammals. Mutations in the ATRX gene, which contains a highly conserved plant homeodomain-like region and is a member of the SWI/SNF2 helicase/ATPase family, give rise to alterations in methylation profiles at the highly repeated sequences, rDNA arrays, a Y-specific satellite and subtelomeric repeats (Gibbons et al., 2000). Thus, genome wide demethylation may occur as a consequence of chromatin remodeling during mammalian development. In yeast, the SWI2/SNF2 family of ATPases, which are members of a large subfamily of the DEAD/H superfamily 2 of nucleic acid-stimulated ATPases and DNA helicases (Carlson and Laurent, 1994), consists of more than 35 members which function in gene transcription, DNA repair and recombination, chromosome segregation and cell cycle progression (Pollard and Peterson, 1998). ATP-dependent chromatin-remodeling complexes that harbor SWI2/SNF2 family members have been termed dACF, dNURF, dCHRAC and Brahma in Drosophi$l a, \mathrm{xMi}-2$ and $\mathrm{xACF}$ in frog and hSWI/SNF, hNURD and hRSF in human (Fry and Peterson, 2001). In mammals, the SWI/SNF-like complexes consist of at least two groups distinguished by their ATPase subunits, BRG1 and BRM. Both human BRG1 and BRM show similar ATPase activity, as shown by their activity on mononucleosomes and nucleosomal arrays using purified proteins (Phelan et al., 1999). However, distinct roles are evident between the mouse SWI/SNF-like complexes, BRG1-related and BRM-related, as shown by deletion of these genes (Reyes et al., 1998; Bultman et al., 2000). Brm-deficient mice are viable, whereas Brgl-deficient mice die during preimplantation development, indicating that $\mathrm{Brgl}$ plays an essential role in the preimplantation embryo. The SWI/SNF-like complexes have chromatin remodeling activity, whereby the alteration of nucleosome conformation utilises energy derived from ATP hydrolysis, possibly by influencing the degree of twist on the nucleosomal DNA. To generate a stable remodeled nucleosomal state through DNA untwisting should require continuous ATP hydrolysis, since the remodeled state should be unstable and rapidly revert back to the original state (Gavin et al., 2001). Analysis of the localization and retention of the yeast SWI/SNF complex to a promoter in a purified system provides some evidence for this. The stability of SWI/SNF binding to the promoter element was enhanced in the presence of nucleosomes acetylated by either SAGA or NuA4 HAT complexes, when compared to binding in the presence of an unmodified nucleosome array (Hassan et al., 2001). This stable promoter occupancy by SWI/SNF was maintained even after the HAT complexes were dissociated. This implies that the activities of activator-recruited HAT complexes and activator-recruited ATPdependent chromatin remodeling complexes are functionally linked. Properly ordered recruitment of these complexes is required to remodel the nucleosome conformation of a promoter region in a stable manner.

Thus, transcriptional activator and repressor proteins are able to interact with each other, bind to the promoter regions of genes, and recruit numerous co-activator and co-repressor proteins including SWI/SNF-like ATPases, HATs, HDACs and methylation-related proteins to regulate the accessibility of components of the general transcriptional machinary. It is, however, still unclear which of these interactions are crucial, and whether the order of recruitment of these factors is critical for appropriate chromatin conformation remodeling, in the regulation of transcriptional activation and repression.

\section{What is the epigenetic status of toti-/pluripoten- tial stem cell nuclei?}

The epigenetic status of adult stem cells and nuclei of considerably differentiated somatic cells can be 'reverted' to that of toti-/pluripotential stem cells by extrinsic and intrinsic factors, respectively. Mouse ES cells, which have a robust capacity to proliferate, are hypomethylated in comparison to considerably differentiated somatic cells, even though such cells possess de novo methylation activity as shown by the stable methylation of Moloney murine leukemia virus sequences after infection of EC cells (Niwa et al., 1983). However, little is known about the epigenetic status of toti-/pluripotential stem cells. One approach towards understanding this question is to address the molecular mechanisms of somatic cell nuclear reprogramming in the process of animal cloning.

The epigenetic status of endogenous nuclei in eggs should indicate what we might expect to find in cloned somatic nuclei following transplantation. One general phenomenon is that of transcriptional repression in zygotes during early developmental stages. In Xenopus laevis, prior to the beginning of zygotic transcription at the midblastula transition (MBT), the genome is replicated rapidly and transcription is repressed. To this end there is an important contribution of the maternal DNA methyltranserase ( $x$ Dnmt 1$)$ enzyme, demonstrated by precocious activation of marker genes following depletion of $x$ Dnmt1 by antisense RNA (Stancheva and Meehan, 2000). The level of 5-methylcytosine in the Xenopus embryo gradually decreases prior to the MBT (Stancheva and Meehan, 2000). Thus, methylation may be involved in maintaining transcriptional repression from cloned somatic nuclei that have been reprogrammed by egg factors. Another mechanism that could be involved in regulating the prevention of zygotic expression is removal of the TATA binding protein (TBP) from the paternal nucleus by the maternal activity of the nucleosome-dependent 
ATPase, ISWI. ISWI is a member of the SWI2/SNF2 superfamily. When nuclei from Xenopus XTC-2 epithelial cells were briefly incubated in Xenopus egg extract, they were remodeled and showed the ISWI-mediated loss of TBP, which is a key component of the basal transcriptional complex (Kikyo et al., 2000). What is important is that ISWI may function as a chromatin remodeler in the process of nuclear reprogramming of cloned somatic nuclei. Disappearance of the TBP removal activity by twofold dilution of the extract implies that this event may occur as an initial step in the process of nuclear reprogramming. However, the overall chromatin conformation of somatic nuclei reprogrammed in eggs is still largely unknown. To address this fully it is essential to know more about the possible factors and events that are involved in the reprogramming process.

In mammals, the timing of the beginning of zygotic expression varies among species, from the 1-2-cell stage in mice, the 4-cell stage in pigs and the 8-16-cell stage in sheep and cows. In all of these species, the successful production of cloned animals by nuclear transplantation implies that DNA synthesis through the cell cycle may not be essential for at least an initial step in the nuclear reprogramming of somatic cells. However, this does not rule out the involvement of cell cycle-related factors in this event. It is of interest that the production of cloned cows succeeds at a relatively high frequency compared to the cloning of mice (Kato et al., 1998; Wakayama et al., 1998; Ogura et al., 2000). One possible explanation is that, for full nuclear reprogramming, somatic nuclei have to be exposed to maternal factors for some time prior to the onset of zygotic tran- scription. Thus, reprogramming would be expected to occur more efficiently in cloned cow and sheep embryos than in cloned mice. In mice, zygotic expression begins from the late 1 cell stage (Latham et al., 1992), while the maternal mRNA pool is dramatically reduced (Worrad et al., 1994). The contents of the egg are therefore dynamically altered between pre- and postzygotic expression. After fertilization, the paternal and maternal genomes are united. The sperm chromatin is decondensed, during which process protamines are replaced with histone $\mathrm{H} 2 \mathrm{~A}$ and $\mathrm{H} 2 \mathrm{~B}$, mediated by the action of nucleoplasmin (Laskey et al., 1993). The maternal pronuclear chromatin remains relatively condensed, and the genomes start to replicate asynchronously (Ferreira and Carmo-Fonseca, 1997). Strikingly, rapid and active demethylation of the paternally derived endogenous $\operatorname{Ig} f 2$ gene and the paternalTKZ751 transgene takes place in mouse zygotes within 4 hours of fertilization, in the absence of DNA replication (Oswald et al., 2000; Mayer et al., 2000). Furthermore, the carboxy-terminal domain of RNA polymerase II, which was predominantly hyperphosphorylated, becomes markedly dephophorylated within several hours of fertilization (Bellier et al., 1997). Eventually, the major epigenetic status of the two genomes must be functionally equivalent and their chromatin structure must be suitable for the onset of zygotic expression. Studies into the nuclear reprogramming of the paternal genome in the oocyte cytoplasm could, therefore, provide insight into the mechanism of nuclear reprogramming of cloned somatic cells. If so, the chromatin of somatic nuclei should be generally decondensed and demethylated shortly after exposure to the egg cytoplasm

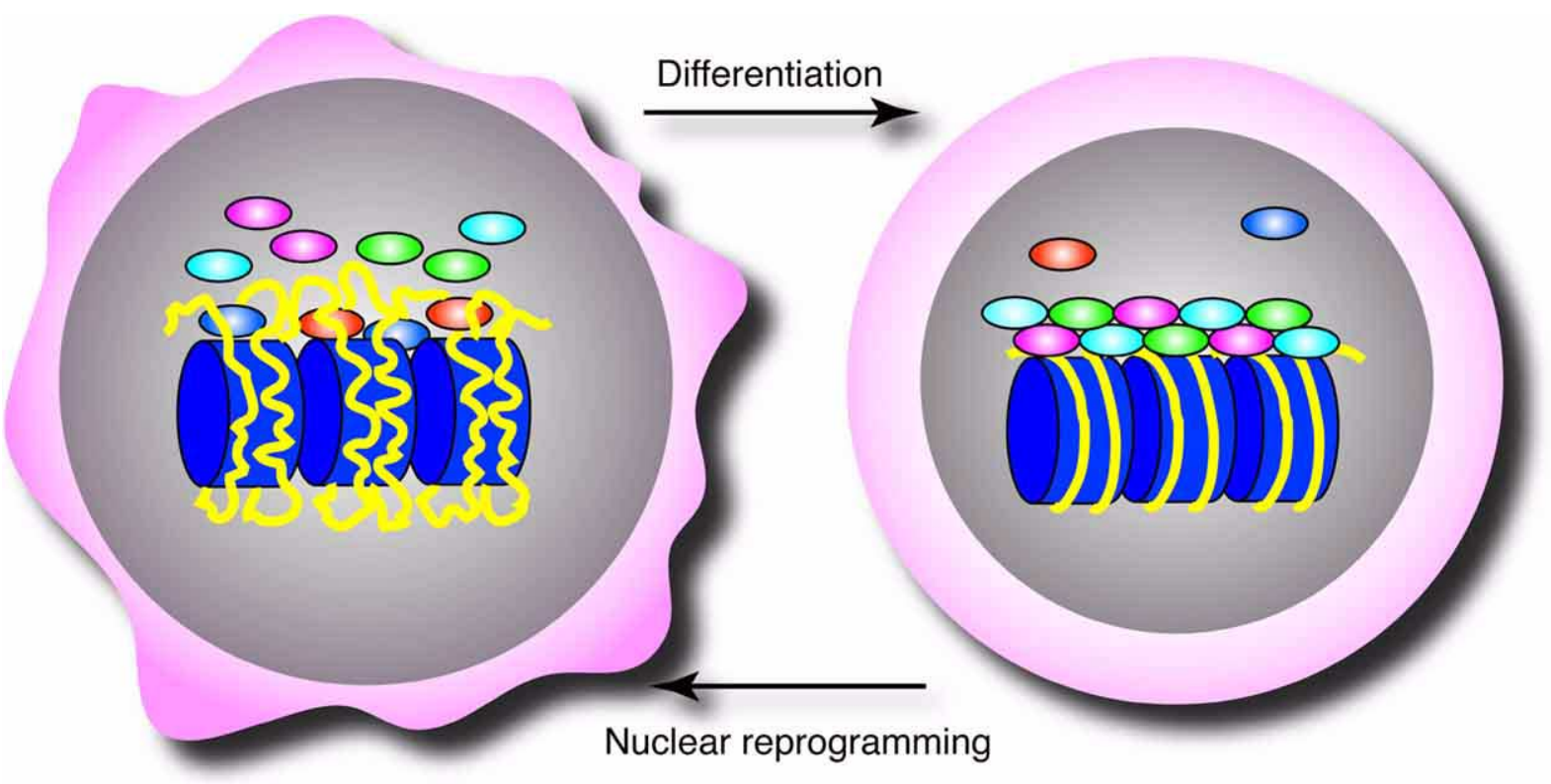

Fig. 3. A model of chromatin remodelling through nuclear reprogramming of somatic cells. In nucleus of a somatic cell, a relatively tight nucleosome structure is formed to precisely regulate transcription of tissue-specific genes. In the nucleus of a pluripotential stem cell, tissue-specific nucleosome formation may be disrupted and a relatively loose nucleosome structure is formed. 
(Fig. 3). This is consistent with the finding in Xenopus that decondensed chromatin structure could be formed by the erasure of TBP from the somatic nucleus via the action of nucleosome-dependent ATPases (Kikyo et al., 2000). However, we do not yet know when a totipotenial cloned nucleus becomes fully established. Other remodeling factors may contribute to further reprogramming of cloned nuclei in Xenopus early development.

For acquisition of totipotential competence, reprogramming of the somatic nucleus by oocyte cytoplasmic factors is undoubtedly evidenced by the production of cloned animals. Similar nuclear reprogramming events are demonstrated by cell hybridization experiments between ES/EG cells and thymic lymphocytes (Tada et al., 1997; Tada et $a l$. , in preparation). This suggests that nuclear reprogramming factors are not specific to oocyte cytoplasm, and production of these factors from stem cells can be stimulated by extrinsic factors during ES/EG cell derivation. Reprogrammed somatic nuclei in hybrid cells retain similar properties to the host stem cell nuclei, since tissue-specific genes are repressed and both nonimprinted and imprinted (in the case of EG cell fusions) genes become demethylated (Tada et al., 1997). Retroposons, such as the Line-1 repetitive elements, the L1 family, and B2 genes, are actively transcribed by RNA polymerase III in the nuclei of ES and EG cells, and their hybrids with somatic cells (unpublished observations). This has also been observed in mouse blastocysts (Packer et al., 1993) and F9 EC cells (White et al., 1989). These findings allow us to speculate that the chromatin of somatic nuclei may be decondensed following hybridization with ES and EG cells (Fig. 3). Factors facilitating loose chromatin formation could therefore play key functions in the reprogramming of cloned somatic nuclei. The regulatory mechanisms, and key factors, that are responsible for reprogramming of somatic nuclei are only now beginning to be elucidated. Greater understanding of these mechanisms will open new and exciting fields in the areas of both basic science and clinical medicine.

Acknowledgments. We thank Dr. Justin F-X Ainscough for critical reading of the manuscript and Dr. Norio Nakatusji, Dr. Hironobu Kimura and Mr. Shin-ya Hatano for discussion. Masako Tada is the recipient of an award from PRESTO, Japan Science and Technology Corporation (JST).

\section{References}

Amit, M., Carpenter, M.K., Inokuma, M.S., Chiu, C.P., Harris, C.P., Waknitz, M.A., Itskovitz-Eldor, J., and Thomson, J.A. 2000. Clonally derived human embryonic stem cell lines maintain pluripotency and proliferative potential for prolonged periods of culture. Dev. Biol., 227: 271-278.

Ballestar, E. and Wolffe, A.P. 2001. Methyl-CpG-binding proteins. Targeting specific gene repression. Eur. J. Biochem., 268: 1-6.

Bauer, W.R., Hayes, J.J., White, J.H., and Wolffe, A.P. 1994. Nucleosome structural changes due to acetylation. J. Mol. Biol., 236: 685-690.

Beard, C., Li, E., and Jaenisch, R. 1995. Loss of methylation activates Xist in somatic but not in embryonic cells. Genes Dev., 9: 2325-2334.
Bellier, S., Chastant, S., Adenot, P., Vincent, M., Renard, J.P., and Bensaude, O. 1997. Nuclear translocation and carboxyl-terminal domain phosphorylation of RNA polymerase II delineate the two phases of zygotic gene activation in mammalian embryos. EMBO J., 16: 62506262.

Bestor, T.H. 1988. Cloning of a mammalian DNA methyltransferase. Gene, 74: 9-12.

Boyes, J., and Bird, A. 1991. DNA methylation inhibits transcription indirectly via a methyl-CpG binding protein. Cell, 64: 1123-1134.

Brandeis, M., Kafri, T., Ariel, M., Chaillet, J.R., McCarrey, J., Razin, A., and Cedar, H. 1993. The ontogeny of allele-specific methylation associated with imprinted genes in the mouse. EMBO J., 12: 3669-3677.

Bultman, S., Gebuhr, T., Yee, D., La Mantia, C., Nicholson, J., Gilliam, A., Randazzo, F., Metzger, D., Chambon, P., Crabtree, G., and Magnuson, T. 2000. A Brg1 null mutation in the mouse reveals functional differences among mammalian SWI/SNF complexes. Mol. Cell, 6: 12871295.

Capecchi, M.R. 1989. The new mouse genetics: altering the genome by gene targeting. Trends Genet., 5: 70-76.

Carlson, M., and Laurent, B.C. 1994. The SNF/SWI family of global transcriptional activators. Curr. Opin. Cell Biol., 6: 396-402.

Chen, L., Shiue, Y.L., Bertolini, L., Medrano, J.F., BonDurant, R.H., and Anderson, G.B. 1999. Establishment of pluripotent cell lines from porcine preimplantation embryos. Theriogenology, 52: 195-212.

Clarke, D.L., Johansson, C.B., Wilbertz, J., Veress, B., Nilsson, E., Karlstrom, H., Lendahl, U., and Frisen, J. 2000. Generalized potential of adult neural stem cells. Science, 288: 1660-1663.

Cross, S.H., Meehan, R.R., Nan, X., and Bird, A. 1997. A component of the transcriptional repressor MeCP1 shares a motif with DNA methyltransferase and HRX proteins. Nat. Genet., 16: 256-259.

Doetsch, F., Caille, I., Lim, D.A., Garcia-Verdugo, J.M., and AlvarezBuylla, A. 1999. Subventricular zone astrocytes are neural stem cells in the adult mammalian brain. Cell, 97, 703-716.

Eggan, K., Akutsu, H., Hochedlinger, K., Rideout, W., 3rd, Yanagimachi, R., and Jaenisch, R. 2000. X-Chromosome inactivation in cloned mouse embryos. Science, 290: 1578-1581.

Evans, M.J. and Kaufman, M.H. 1981. Establishment in culture of pluripotential cells from mouse embryos. Nature, 292: 154-156.

Ferreira, J., and Carmo-Fonseca, M. 1997. Genome replication in early mouse embryos follows a defined temporal and spatial order. J. Cell Sci., 110: 889-897.

Fry, C.J. and Peterson, C.L. 2001. Chromatin remodeling enzymes: who's on first? Curr. Biol., 11: 185-197.

Gavin, I., Horn, P.J., and Peterson, C.L. 2001. SWI/SNF chromatin remodeling requires changes in DNA topology. Mol. Cell, 7: 97-104.

Gibbons, R.J., McDowell, T.L., Raman, S., O'Rourke, D.M., Garrick, D., Ayyub, H., and Higgs, D.R. 2000. Mutations in ATRX, encoding a SWI/SNF-like protein, cause diverse changes in the pattern of DNA methylation. Nat. Genet., 24: 368-371.

Ginsburg, M., Snow, M.H., and McLaren, A. 1990. Primordial germ cells in the mouse embryo during gastrulation. Development, 110: 521-528.

Gurdon, J. 1962. The developmental capacity of nuclei taken from intestinal epithelial cells of feeding tadpoles. J. Embryol. Exp. Morphol., 10: 622-640.

Hassan, A.H., Neely, K.E., and Workman, J.L. 2001. Histone acetyltransferase complexes stabilize SWI/SNF binding to promoter nucleosomes. Cell, 104: 817-827.

Hendrich, B. and Bird, A. 1998. Identification and characterization of a family of mammalian methyl-CpG binding proteins. Mol. Cell Biol., 18: 6538-6547.

Hendrich, B. Guy, J., Ramsahoye, B., Wilson, V.A., and Bird, A. 2001. Closely related proteins MBD2 and MBD3 play distinctive but interacting roles in mouse development. Genes Dev., 15: 710-723. 
Howell, C.Y., Bestor, T.H., Ding, F., Latham, K.E., Mertineit, C., Trasler, J.M., and Chaillet, J.R. 2001. Genomic imprinting disrupted by a maternal effect mutation in the Dnmt1 gene. Cell, 104: 829-838.

Iwasaki, S., Campbell, K.H., Galli, C., and Akiyama, K. 2000. Production of live calves derived from embryonic stem-like cells aggregated with tetraploid embryos. Biol. Reprod., 62: 470-475.

Johansson, C.B., Momma, S., Clarke, D.L., Risling, M., Lendahl, U., and Frisen, J. 1999. Identification of a neural stem cell in the adult mammalian central nervous system. Cell, 96: 25-34.

Jones, P.A. 1999. The DNA methylation paradox. Trends Genet., 15: 34 37.

Jones, P.L., Veenstra, G.J.C., Wade, P.A., Vermaak, D., Kass, S.U., Landsberger, N., Strouboulis, J., and Wolffe, A.P. 1998. Methylated DNA and MeCP2 recruit histone deacetylase to repress transcription. Nature Genet., 19: 187-191.

Kafri, T., Ariel, M., Brandeis, M., Shemer, R., Urvan, L., McCarrey, J., Cedar, H., and Razin, A. 1992. Developmental pattern of gene-specific DNA methylation in the mouse embryo and germ line. Genes Dev., 6 : 705-714.

Kato, Y., Tani, T., Sotomaru, Y., Kurokawa, K., Kato, J., Doguchi, H., Yasue, H., and Tsunoda, Y. 1998. Eight calves cloned from somatic cells of a single adult. Science, 282: 2095-2098.

Kawasaki, H., Mizuseki, K., Nishikawa, S., Kaneko, S., Kuwana, Y., Nakanishi, S., Nishikawa, S.I., and Sasai, Y. 2000. Induction of midbrain dopaminergic neurons from ES cells by stromal cell-derived inducing activity. Neuron, 28: $31-40$.

Kawase, E., Yamazaki, Y., Yagi, T., Yanagimachi, R., and Pedersen, R.A. 2000. Mouse embryonic stem (ES) cell lines established from neuronal cell-derived cloned blastocysts. Genesis, 28: 156-163.

Keohane, A.M., Lavender, J.S., O'Neill, L.P., and Turner, B.M. 1998. Histone acetylation and X inactivation. Dev. Genet., 22: 65-73.

Kikyo, N., Wade, P.A., Guschin, D., Ge, H., and Wolffe, A.P. 2000. Active remodeling of somatic nuclei in egg cytoplasm by the nucleosomal ATPase ISWI. Science, 289: 2360-2362.

Labosky, P.A., Barlow, D.P., and Hogan, B.L.M. 1994. Mouse embryonic germ (EG) cell lines: transmission through the germline and differences in the methylation imprint of insulin-like growth factor 2 receptor $(I g f 2 r)$ gene compared with embryonic stem (ES) cell lines. Development, 120: 3197-3204.

Lagasse, E., Connors, H., Al-Dhalimy, M., Reitsma, M., Dohse, M., Osborne, L., Wang, X., Finegold, M., Weissman, I. L., and Grompe, M. 2000. Purified hematopoietic stem cells can differentiate into hepatocytes in vivo. Nat. Med., 6: 1229-1234.

Lanza, R.P., Cibelli, J.B., Blackwell, C., Cristofalo, V.J., Francis, M.K., Baerlocher, G.M., Mak, J., Schertzer, M., Chavez, E.A., Sawyer, N., Lansdorp, P.M., and West, M.D. 2000. Extension of cell life-span and telomere length in animals cloned from senescent somatic cells. Science, 288: 665-669.

Laskey, R.A., Mills, A.D., Philpott, A., Leno, G.H., Dilworth, S.M., and Dingwall, C. 1993. The role of nucleoplasmin in chromatin assembly and disassembly. Philos. Trans. R. Soc. Lond. B Biol. Sci., 339: 263269.

Latham, K.E., Solter, D., and Schultz, R.M. 1992. Acquisition of a transcriptionally permissive state during the 1-cell stage of mouse embryogenesis. Dev. Biol., 149: 457-462.

Lawson, K.A., Dunn, N.R., Roelen, B.A., Zeinstra, L.M., Davis, A.M., Wright, C.V., Korving, J.P., and Hogan, B.L. 1999. Bmp4 is required for the generation of primordial germ cells in the mouse embryo. Genes Dev., 13: 424-436.

Li, E., Beard, C., and Jaenisch, R. 1993. Role for DNA methylation in genomic imprinting. Nature, 366: 362-365.

Li, E., Bestor, T.H., and Jaenisch, R. 1992. Targeted mutation of the DNA methyltransferase gene results in embryonic lethality. Cell, 69: 915-926.
Martin, G.R. 1980. Teratocarcinomas and mammalian embryogenesis. Science, 209: 768-776.

Martin, G.R. 1981. Isolation of a pluripotent cell line from early mouse embryos cultured in medium conditioned by teratocarcinoma stem cells. Proc. Natl. Acad. Sci. USA, 78: 7634-7638.

Matsui, Y., Zsebo, K., and Hogan, B.L. 1992. Derivation of pluripotential embryonic stem cells from murine primordial germ cells in culture. Cell, 70: $841-847$

Mayer, W., Niveleau, A., Walter, J., Fundele, R., and Haaf, T. 2000. Demethylation of the zygotic paternal genome. Nature, 403: 501-502.

McCreath, K.J., Howcroft, J., Campbell, K.H., Colman, A., Schnieke, A.E., and Kind, A.J. 2000. Production of gene-targeted sheep by nuclear transfer from cultured somatic cells. Nature, 405: 1066-1069.

Momma, S., Johansson, C.B., and Frisen, J. 2000. Get to know your stem cells. Curr. Opin. Neurobiol., 10: 45-49.

Monk, M., Boubelik, M., and Lehnert, S. 1987. Temporal and regional changes in DNA methylation in the embryonic, extraembryonic and germ cell lineages during mouse embryo development. Development, 99: $371-382$.

Monk, M. and Harper, M.I. 1979. Sequential X chromosome inactivation coupled with cellular differentiation in early mouse embryos. Nature, 281: $311-313$.

Monk, M. and McLaren, A. 1981. X-chromosome activity in foetal germ cells. J. Embryol. Exp. Morph., 63: 75-84.

Munsie, M.J., Michalska, A.E., O'Brien, C.M., Trounson, A.O., Pera, M.F., and Mountford, P.S. 2000. Isolation of pluripotent embryonic stem cells from reprogrammed adult mouse somatic cell nuclei. Curr. Biol., 10: 989-992.

Nan, X., Meehan, R.R., and Bird, A. 1993. Dissection of the methyl-CpG binding domain from the chromosomal protein MeCP2. Nucleic Acids Res., 21: 4886-4892.

Nan, X., Ng, H.H., Johnson, C.A., Laherty, C.D., Turner, B.M., Eisenman, R.N., and Bird, A. 1998. Transcriptional repression by the methyl-CpGbinding protein MeCP2 involves a histon deacetylase complex. Nature, 393: $386-389$.

Newell-Price, J., Clark, A.J., and King, P. 2000. DNA methylation and silencing of gene expression. Trends Endocrinol. Metab., 11: 142-148.

Ng, H.H., Zhang, Y., Hendrich, B., Johnson, C.A., Turner, B.M., Erdjument-Bromage, H., Tempst, P., Reinberg, D., and Bird, A. 1999. MBD2 is a transcriptional repressor belonging to the MeCP1 histone deacetylase complex. Nat. Genet., 23: 58-61.

Niwa, O., Yokota, Y., Ishida, H., and Sugahara, T. 1983. Independent mechanisms involved in supression of the Moloney leukemia virus genome during differentiation of murine teratocarcinoma cells. Cell, $\mathbf{3 2}$ : $1105-1113$.

Notarianni, E., Galli, C., Laurie, S., Moor, R.M., and Evans, M.J. 1991. Derivation of pluripotent, embryonic cell lines from the pig and sheep. $J$. Reprod. Fertil. Suppl., 43: 255-260.

Obata, Y., Kaneko-Ishino, T., Koide, T., Takai, Y., Ueda, T., Domeki, I., Shiroishi, T., Ishino, F., and Kono, T. 1998. Disruption of primary imprinting during oocyte growth leads to the modified expression of imprinted genes during embryogenesis. Development, 125: 1553-1560.

Ogura, A., Inoue, K., Takano, K., Wakayama, T., and Yanagimachi, R. 2000. Birth of mice after nuclear transfer by electrofusion using tail tip cells. Mol. Reprod. Dev., 57: 55-59.

Oh, S.H., Miyazaki, M., Kouchi, H., Inoue, Y., Sakaguchi, M., Tsuji, T., Shima, N., Higashio, K., and Namba, M. 2000. Hepatocyte growth factor induces differentiation of adult rat bone marrow cells into a hepatocyte lineage in vitro. Biochem. Biophys. Res. Commun., 279: 500504.

Okano, M., Bell, D.W., Haber, D.A., and Li, E. 1999. DNA methyltransferases Dnmt3a and Dnmt3b are essential for de novo methylation and mammalian development. Cell, 99: 247-257. 
Okano, M., Xie, S., and Li, E. 1998. Cloning and characterization of a family of novel mammalian DNA (cytosine-5) methyltransferases. Nat. Genet., 19: 219-220.

Onishi, A., Iwamoto, M., Akita, T., Mikawa, S., Takeda, K., Awata, T., Hanada, H., and Perry, A.C. 2000. Pig cloning by microinjection of fetal fibroblast nuclei. Science, 289: 1188-1190.

Oswald, J., Engemann, S., Lane, N., Mayer, W., Olek, A., Fundele, R., Dean, W., Reik, W., and Walter, J. 2000. Active demethylation of the paternal genome in the mouse zygote. Curr. Biol., 10: 475-478.

Packer, A.I., Manova, K., and Bachvarova, R.F. 1993. A discrete LINE-1 transcript in mouse blastocysts. Dev. Biol., 157: 281-283.

Petersen, B.E., Bowen, W.C., Patrene, K.D., Mars, W.M., Sullivan, A.K., Murase, N., Boggs, S.S., Greenberger, J.S., and Goff, J.P. 1999. Bone marrow as a potential source of hepatic oval cells. Science, 284: 11681170.

Phelan, M.L., Sif, S., Narlikar, G.J., and Kingston, R.E. 1999. Reconstitution of a core chromatin remodeling complex from SWI/SNF subunits. Mol. Cell, 3: 247-253.

Pierce, G.B. 1967. Teratocarcinoma: model for a developmental concept of cancer. Curr. Top. Dev. Biol., 2: 223-246.

Polejaeva, I.A., Chen, S.H., Vaught, T.D., Page, R.L., Mullins, J., Ball, S., Dai, Y., Boone, J., Walker, S., Ayares, D.L., Colman, A., and Campbell, K.H. 2000. Cloned pigs produced by nuclear transfer from adult somatic cells. Nature, 407: 86-90.

Pollard, K.J. and Peterson, C.L. 1998. Chromatin remodeling: a marriage between two families? Bioessays, 20: 771-780.

Razin, A. and Kafri, T. 1994. DNA methylation from embryo to adult. Prog. Nucleic Acid Res. Mol. Biol., 48: 53-81.

Resnick, J.L., Bixler, L.S., Cheng, L., and Donovan, P. 1992. Long-term proliferation of mouse primordial germ cells in culture. Nature, 359: $550-551$.

Reyes, J.C., Barra, J., Muchardt, C., Camus, A., Babinet, C., and Yaniv, M. 1998. Altered control of cellular proliferation in the absence of mammalian brahma (SNF2alpha). EMBO J., 17: 6979-6991.

Rideout, W.M., 3rd, Wakayama, T., Wutz, A., Eggan, K., Jackson-Grusby, L., Dausman, J., Yanagimachi, R., and Jaenisch, R. 2000. Generation of mice from wild-type and targeted ES cells by nuclear cloning. Nat. Genet., 24: 109-110.

Schoonjans, L., Albright, G.M., Li, J.L., Collen, D., and Moreadith, R.W. 1996. Pluripotential rabbit embryonic stem (ES) cells are capable of forming overt coat color chimeras following injection into blastocysts. Mol. Reprod. Dev., 45: 439-443.

Shamblott, M.J., Axelman, J., Wang, S., Bugg, E.M., Littlefield, J.W., Donovan, P.J., Blumenthal, P.D., Huggins, G.R., and Gearhart, J.D. 1998. Derivation of pluripotent stem cells from cultured human primordial germ cells. Proc. Natl. Acad. Sci. USA, 95: 13726-13731.

Shim, H., Gutierrez-Adan, A., Chen, L.R., BonDurant, R.H., Behboodi, E., and Anderson, G.B. 1997. Isolation of pluripotent stem cells from cultured porcine primordial germ cells. Biol. Reprod., 57: 1089-1095.

Snow, M.H.L. and Monk, M. 1983. Emergence and migration of mouse primordial germ cells. In "In current problems in germ cell differentiation" (A. McLaren and C.C. Wylie, Eds.), pp. 115-135. Cambridge University Press, Cambridge.

Stancheva, I. and Meehan, R.R. 2000. Transient depletion of xDnmt1 leads to premature gene activation in Xenopus embryos. Genes Dev., 14: 313-327.

Suemori, H., Tada, T., Torii, R., Hosoi, Y., Kobayashi, K., Imahie, H., Kondo, Y., Iritani, A., Nakatsuji, N. 2001. Establishment of embryonic stem cell lines from cynomologus monkey blastocysts produced by in vitro fertilization. Dev. Dyn. in press.

Szabo, P.E. and Mann, J.R. 1995. Biallelic expression of imprinted genes in the mouse germ line: implications for erasure, establishment, and mechanisms of genomic imprinting. Genes Dev., 9: 1857-1868.
Tada, M., Tada, T., Lefebvre, L., Barton, S.C., and Surani, M.A. 1997. Embryonic germ cells induce epigenetic reprogramming of somatic nucleus in hybrid cells. EMBO J., 16: 6510-6520.

Tada, T., Obata, Y., Tada, M., Goto, Y., Nakatsuji, N., Tan, S., Kono, T., and Takagi, N. 2000. Imprint switching for non-random X-chromosome inactivation during mouse oocyte growth. Development, 127: 31013105.

Tada, T., Tada, M., Hilton, K., Barton, S.C., Sado, T., Takagi, N., and Surani, M.A. 1998. Epigenotype switching of imprintable loci in embryonic germ cells. Dev. Gene Evol., 207: 551-561.

Tada, M., Takahama, Y., Abe, K., Nakatsuji, N., and Tada, T. 2001. Nuclear reprogramming of somatic cells by in vitro hybridization with ES cells. In preparation.

Takagi, N., Sugawara, O., and Sasaki, M. 1982. Regional and temporal changes in the pattern of X-chromosome replication during the early post-implantation development of the female mouse. Chromosoma, $\mathbf{8 5}$ : 275-286.

Tate, P., Skarnes, W., and Bird, A. 1996. The methyl-CpG binding protein $\mathrm{MeCP} 2$ is essential for embryonic development in the mouse. Nat. Genet., 12: 205-208.

Temple, S. and Alvarez-Buylla, A. 1999. Stem cells in the adult mammalian central nervous system. Curr. Opin. Neurobiol., 9: 135-141.

Thomson, J.A., Itskovitz-Eldor, J., Shapiro, S.S., Waknitz, M.A., Swiergiel, J.J., Marshall, V. S., and Jones, J.M. 1998. Embryonic stem cell lines derived from human blastocysts. Science, 282: 1145-1147.

Thomson, J.A., Kalishman, J., Golos, T.G., Durning, M., Harris, C.P., Becker, R.A., and Hearn, J.P. 1995. Isolation of a primate embryonic stem cell line. Proc. Natl. Acad. Sci. USA, 92: 7844-7848.

Thomson, J.A., Kalishman, J., Golos, T.G., Durning, M., Harris, C.P., and Hearn, J.P. 1996. Pluripotent cell lines derived from common marmoset (Callithrix jacchus) blastocysts. Biol. Reprod., 55: 254-259.

Tong, J.K., Hassig, C.A., Schnitzler, G.R., Kingston, R.E., and Schreiber, S.L. 1998. Chromatin deacetylation by an ATP-dependent nucleosome remodelling complex. Nature, 395: 917-921.

Tse, C., Sera, T., Wolffe, A.P., and Hansen, J.C. 1998. Disruption of higher-order folding by core histone acetylation dramatically enhances transcription of nucleosomal arrays by RNA polymerase III. Mol. Cell Biol., 18: 4629-4638.

Turner, B.M. 1993. Decoding the nucleosome. Cell, 75: 5-8.

Vassilieva, S., Guan, K., Pich, U., and Wobus, A.M. 2000. Establishment of SSEA-1-and Oct-4-expressing rat embryonic stem-like cell lines and effects of cytokines of the IL-6 family on clonal growth. Exp. Cell Res., 258: $361-373$.

Wade, P.A., Gegonne, A., Jones, P.L., Ballestar, E., Aubry, F., and Wolffe, A.P. 1999. Mi-2 complex couples DNA methylation to chromatin remodelling and histone deacetylation. Nat. Genet., 23: 62-66.

Wakayama, T., Perry, A.F.C., Zuccotti, M., Johnson, K.R., and Yanagimachi, R. 1998. Full-term development of mice from enucleated oocytes injected with cumulus cell nuclei. Nature, 394: 369-374.

Wakayama, T., Shinkai, Y., Tamashiro, K.L., Niida, H., Blanchard, D.C., Blanchard, R.J., Ogura, A., Tanemura, K., Tachibana, M., Perry, A.C., Colgan, D.F., Mombaerts, P., and Yanagimachi, R. 2000. Cloning of mice to six generations. Nature, 407: 318-319.

White, R.J., Stott, D., and Rigby, P.W. 1989. Regulation of RNA polymerase III transcription in response to F9 embryonal carcinoma stem cell differentiation. Cell, 59: 1081-1092.

Wilmut, I., Schnieke, A.E., McWhir, J., Kind, A.J., and Campbell, K.H.S. 1997. Viable offspring derived from fetal and adult mammalian cells. Nature, 385: 810-813.

Wolffe, A.P. 1996. Histone deacetylase: a regulator of transcription. Science, 272: 371-372.

Worrad, D.M., Ram, P.T., and Schultz, R.M. 1994. Regulation of gene expression in the mouse oocyte and early preimplantation embryo: 
developmental changes in Sp1 and TATA box-binding protein, TBP. Development, 120: 2347-2357.

Yamashita, J., Itoh, H., Hirashima, M., Ogawa, M., Nishikawa, S., Yurugi, T., Naito, M., and Nakao, K. 2000. Flk1-positive cells derived from embryonic stem cells serve as vascular progenitors. Nature, 408: 92-96.

Yeom, Y.I., Fuhrmann, G., Ovitt, C.E., Brehm, A., Ohbo, K., Gross, M., Hubner, K., and Scholer, H.R. 1996. Germline regulatory element of Oct-4 specific for the totipotent cycle of embryonal cells. Development, 122: $881-894$.

Yoshimizu, T., Obinata, M., and Matsui, Y. 2001. Stage-specific tissue and cell interactions play key roles in mouse germ cell specification. Development, 128: 481-490.
Yoshimizu, T., Sugiyama, N., De Felice, M., Yeom, Y.I., Ohbo, K., Masuko, K., Obinata, M., Abe, K., Scholer, H.R., and Matsui, Y. 1999. Germline-specific expression of the Oct-4/green fluorescent protein (GFP) transgene in mice. Dev. Growth Differ., 41: 675-684.

Zhang, Y., LeRoy, G., Seelig, H.P., Lane, W.S., and Reinberg, D. 1998. The dermatomyositis-specific autoantigen Mi2 is a component of a complex containing histone deacetylase and nucleosome remodeling activities. Cell, 95: 279-289.

(Received for publication, May 7, 2001

and accepted, May 25, 2001) 